\title{
RADIOLOGICAL CHARACTERISTICS OF DECOMMISSIONING WASTE FROM A CANDU REACTOR
}

\author{
DONG-KEUN CHO ${ }^{1 *}$, HEUI-JOO CHOI ${ }^{1}$, RIZWAN AHMED ${ }^{2}$, and GYUNYOUNG HEO ${ }^{2}$ \\ ${ }^{1}$ Korea Atomic Energy Research Institute \\ 150 Dukjin-dong, Yuseong, Daejeon, Republic of Korea 305-353 \\ ${ }^{2}$ Department of Nuclear Engineering, Kyung Hee University \\ 1 Seochoeon-dong, Giheung, Yongin, Gyeonggi, Republic of Korea 446-701 \\ ${ }^{*}$ Corresponding author. E-mail : dkcho@kaeri.re.kr
}

Received March 25, 2011

Accepted for Publication August 09, 2011

\begin{abstract}
The radiological characteristics for waste classification were assessed for neutron-activated decommissioning wastes from a CANDU reactor. The MCNP/ORIGEN2 code system was used for the source term analysis. The neutron flux and activation cross-section library for each structural component generated by MCNP simulation were used in the radionuclide buildup calculation in ORIGEN2. The specific activities of the relevant radionuclides in the activated metal waste were compared with the specified limits of the specific activities listed in the Korean standard and 10 CFR 61. The time-average full-core model of Wolsong Unit 1 was used as the neutron source for activation of in-core and ex-core structural components. The approximated levels of the neutron flux and cross-section, irradiated fuel composition, and a geometry simplification revealing good reliability in a previous study were used in the source term calculation as well. The results revealed the radioactivity, decay heat, hazard index, mass, and solid volume for the activated decommissioning waste to be $1.04 \times 10^{16}$ Bq, $2.09 \times 10^{3} \mathrm{~W}, 5.31 \times 10^{14} \mathrm{~m}^{3}$-water, $4.69 \times 10^{5} \mathrm{~kg}$, and $7.38 \times 10^{1} \mathrm{~m}^{3}$, respectively. According to both Korean and US standards, the activated waste of the pressure tubes, calandria tubes, reactivity devices, and reactivity device supporters was greater than Class $\mathrm{C}$, which should be disposed of in a deep geological disposal repository, whereas the side structural components were classified as low- and intermediate-level waste, which can be disposed of in a land disposal repository. Finally, this study confirmed that, regardless of the cooling time of the waste, $15 \%$ of the decommissioning waste cannot be disposed of in a land disposal repository. It is expected that the source terms and waste classification evaluated through this study can be widely used to establish a decommissioning/disposal strategy and fuel cycle analysis for CANDU reactors.
\end{abstract}

KEYWORDS : Source Term Characterization, Waste Classification, Decommissioning Waste, Monte Carlo Simulation, CANDU Reactor

\section{INTRODUCTION}

South Korea has both PWR and Canada deuterium uranium (CANDU) reactors: there are four CANDUs among the twenty-one commercial reactors currently in operation [1]. According to the $5^{\text {th }}$ Basic Plan of Electricity Supply and Demand announced by the Korean government, thirteen PWRs will be built by 2024 , resulting in a total nuclear capacity of 48.5\% [2]. As installations age and nuclear capacity increases, the Korean government and the Korean nuclear industry have begun R\&D projects in order to estimate the decommissioning costs of the commercial nuclear reactors in Korea [3-5].

The source terms of the decommissioning waste are directly concerned with the determination of decommissioning and decontamination technologies, prediction of exposure to workers, determination of decay periods up to the initiation of the decommissioning, and safety analyses [6]. Therefore, reasonable source term estimations are necessary to exclude conservative designs of the decommissioning procedures and disposal systems. However, no document that describes the detailed source terms and classifications of decommissioning waste from a CANDU reactor has been published to date.

In Reference 7, Cho et al. described a method to establish a burned full-core model for a Monte Carlo simulation, as a neutron source to activate the structural components in the inner and outer cores, and to calculate the source terms of the decommissioning waste from a CANDU reactor. This paper proposed a simplified burned full-core model with reasonable calculation accuracy and a short computer runtime. Furthermore, in Reference 8, 
Cho et al. described the verification results of the established model by comparing the estimated nuclide inventory from the analysis system with the measured inventory in the structural components. However, no one has yet extensively evaluated the source term characteristics and resulting classification of the decommissioning waste from a CANDU reactor.

In this study, the radiological characteristics of decommissioning waste were evaluated in detail for all structural components of a CANDU reactor. First, we explain the evaluation method and neutron source model for the activation of the structural component; then, we describe the source terms and resulting waste classifications.

\section{REFERENCE REACTOR}

This study is based on Wolsong Unit 1, the first CANDU 6 type reactor in South Korea, with a total reactor power of 2,061 MWth, which started its commercial operation in 1983. The on-power refueling by adopting the $\mathrm{D}_{2} \mathrm{O}$ moderator and natural uranium fuel is a unique feature of this reactor. More information on the features of Wolsong Unit 1 is explained in References 7 and 9.

\section{SOURCE TERM CHARACTERIZATION METHOD}

\subsection{Calculation of Neutron-Induced Activity}

The number density change rate of a particular nuclide, $N_{i}$, in an activated material can be expressed using Eq. (1):

$$
\frac{d N_{i}}{d t}=\sum_{j} \delta_{i j} \lambda_{j} N_{j}+\sum_{k} f_{i k} \sigma_{k} \phi N_{k}-\left(\lambda_{i}+\sigma_{i} \phi\right) N_{i}
$$

where

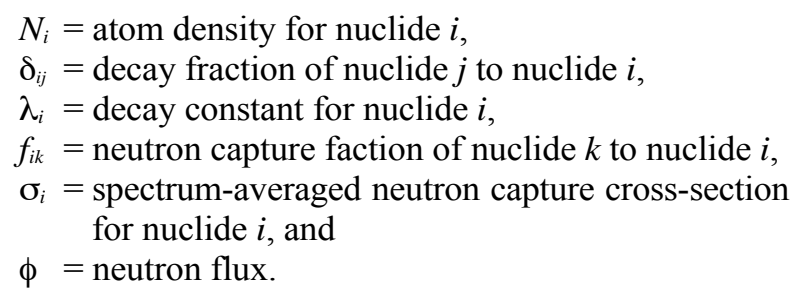

As a first step, information on the spatial and energy distribution of the neutron flux and neutron capture cross-sections throughout the nuclear system is needed to solve Eq. (1). The neutron flux and cross-sections are then used for Eq. (1) to obtain the level of activity according to the reactor irradiation history and subsequent decay time. Figure 1 shows the methodology involved in an inventory calculation of activated decommissioning wastes.

In this study, a CASE (CANDU Activated Sourceterm Evaluator) program that employs MCNP and ORIGEN2 was used as the source term characterization tool. This program has the capability to prepare the MCNP input, to run MCNP for neutron flux and cross-section calculation, to prepare the ORIGEN2 input for activation analysis for the region of interest, to process the ORIGEN2 output, and to compare the estimated specific activity of the activated waste with the waste classification standard.

In the CASE program, the MCNP [10] is used to transport the neutrons from the irradiated fuel to a structural component to calculate the neutron flux and cross-sections for selected zones. After obtaining the neutron flux and cross-sections from the MCNP simulation, these values are used in the ORIGEN2 [11] calculations to obtain the radionuclide inventory for a selected zone at time $t$. Because ORIGEN2 uses one-group collapsed capture cross-sections, the cross-sections required to solve Eq. (1) for a specific region of interest were obtained through Eq. (2) using the F4 and FM4 tally in the MCNP simulation:

$$
\bar{\sigma}=\frac{\iint \sigma(E) \phi(E) d E d V}{\iint \phi(E) d E d V},
$$

where

$\bar{\sigma} \quad=$ one-group collapsed capture cross-section for the selected zone,

$\sigma(E)=$ energy-dependent capture cross-section, and

$\phi(E)=$ energy-dependent neutron flux for the selected zone.

The integration in Eq. (2) is conducted over the range of volume of the selected zone for activity calculation. The one-group collapsed capture cross-sections were generated for forty nuclides considering the initial composition of the structural materials and their activation products, as well as the decay products of the activation products.

Note that constant neutron flux and cross-sections as a function of irradiation time were assumed in the source term characterization throughout this paper. A detailed explanation for the source term calculation procedure, based on Fig. 1, follows. The 'calculation of neutron activation for the selected zone' in the ORIGEN2 block shown in Fig. 1 is performed using Eq. (1), and the 'calculation of cross-sections collapsing' in the MCNP block is carried out using Eq. (2).

\subsection{Neutron Transport Calculation}

Because the neutron spectrum and flux level in the structural components vary from the inner core to the outer core and reactor operation time, it is important to use appropriate cross-section and neutron flux in Eq. (1) to accurately estimate the radioactive nuclide inventory produced by the $(\mathrm{n}, r)$ reaction $[12,13]$.

\subsubsection{Reactor Operation Condition}

Because the neutron flux of the structural component continuously fluctuates as the reactor operates, the timeaverage full-core model definitely generates a more 


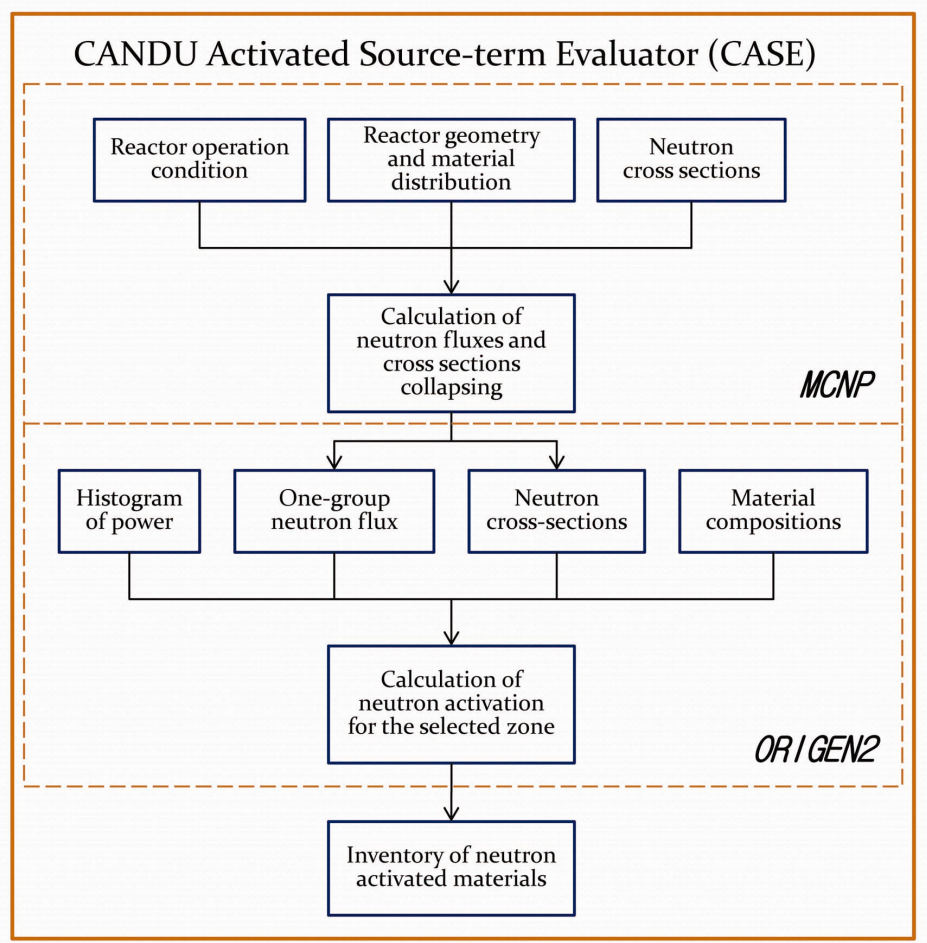

Fig. 1. Procedure for Neutron-induced Activity Calculations

reliable average neutron flux in the structural component than the snapshot full-core model, which describes the reactor condition at arbitrary time $t$ and results in a neutron flux and cross-sections at time $t$ [7]. It is important to use the average neutron flux of the component in the activation calculation, because it is very difficult to consider a varying neutron flux as a function of operation time. Therefore, a time-average pseudo full-core model was established for the Monte Carlo simulation to obtain the time-average neutron flux and relevant cross-sections for the region of interest.

First, the time-average burnup value was generated for each fuel bundle because the depleted core condition is represented primarily by the irradiated fuel composition in the MCNP calculation. Note that the irradiated fuel composition corresponds to the fuel burnup. In the timeaverage calculation, the burnup for each fuel bundle in the unit of $\mathrm{MWd} / \mathrm{tU}$ was averaged over the residence time for the fuel in the core, as described using Eq. (3):

$$
\bar{B}=\frac{1}{\Delta t} \int_{t 1}^{t 2} B(t) d t,
$$

where $t_{1}$ and $t_{2}$ represent the beginning and end times of the reactor operation in days, respectively, and $\Delta t=t_{2}-t_{l}$. Therefore, the average burnup of $\bar{B}$ is different for each bundle because the specific power is dependent on the location and residence time of each fuel bundle. In this study, the historical burnup distribution data of Wolsong Unit 1 from 6,579 to 7,672 effective full-power days (EFPD) calculated by the PPV/RFSP core management system was used to generate the time-average burnup value for each bundle.

\subsubsection{Reactor Geometry and Materials}

\subsubsection{Fuel Components}

The level of simplification for the geometry and nuclide composition of the fuel bundle is an important concern in establishing a neutron source model for the MCNP simulation, as described in Fig. 1. The bundleaverage homogeneous model was considered, where the fuel bundle and coolant in Fig. 2(a) are described as only one region, as in Fig. 2(b), and the nuclide compositions are averaged over the fuel, cladding, and coolant, as shown in Fig. 2. The mass and volume of the irradiated fuel, cladding, and coolant were preserved in the homogenization. This simplification level was also been justified in References 7 and 8.

The CANDU core is comprised of 4,560 fuel bundles and a corresponding 168,720 fuel rods. The irradiated fuel composition corresponding to the time-average burnup value in addition to the coolant composition was assigned 
to each region of the fuel bundle and coolant in Fig. 2(b). For this, the burnup-dependent isotopic compositions that represent the irradiated fuel state were generated using WIMS-AECL. This code considers 16 actinides, 46 fission products, and two pseudo fission products. In the lattice calculation with WIMS-AECL, a unit cell consisting of a single fuel channel, as shown in Fig. 2(a), and a nominal amount of moderator were considered. It is well known that the lattice calculation provides information on the variation of cross-sections and isotopic composition with fuel burnup, on the reactivity coefficients and power distribution in the fuel elements across the fuel bundle, and on the cell-average crosssections to be used in the core calculations. Nominal design data for a fuel channel and fuel bundle were used for burnupdependent isotopic compositions.

Based on the pre-generated burnup-dependent isotopic compositions, the isotopic number densities of the major actinides and fission products were assigned to represent the irradiated fuel. Because consideration of all the actinides and fission products requires a significant amount of computational memory and effort in order to establish a neutron source model for a Monte Carlo simulation, only 14 nuclides, ${ }^{235} \mathrm{U},{ }^{238} \mathrm{U},{ }^{239} \mathrm{Pu},{ }^{240} \mathrm{Pu},{ }^{241} \mathrm{Pu},{ }^{103} \mathrm{Rh},{ }^{105} \mathrm{Rh}$, ${ }^{131} \mathrm{Xe},{ }^{133} \mathrm{Cs},{ }^{135} \mathrm{Xe},{ }^{143} \mathrm{Nd},{ }^{147} \mathrm{Pm},{ }^{149} \mathrm{Sm}$, and ${ }^{151} \mathrm{Sm}$, were considered. These 14 nuclides were considered because this consideration level had almost the same neutron flux distribution and group-collapsed cross-sections as the consideration level of all the nuclides dealt with by WIMSAECL, as described in References 7 and 8.

Because it is difficult to assign the actinides and fission products to all irradiated fuels, a modeling program that automatically generates the geometry and fuel composition corresponding to the respective burnup of the fuel bundle required for the MCNP input was developed. This program, called BUNDL, has built-in burnup-dependent isotopic compositions that have been generated using the WIMSAECL code. Once the burnup of the irradiated fuel bundle is read, the program calculates the isotopic number densities for the actinides and fission products corresponding to the burnup; then, the number densities for the 14 previously mentioned nuclides are given for the region to make an MCNP input.

\subsubsection{Non-fuel Components}

For non-fuel components, the pressure tubes, calandria tubes, and calandira tank were described explicitly. Reactivity devices, namely, zone control units (ZCUs), mechanical control absorbers (MCAs), adjusters (ADJs), and shutoff rods (SORs), were included in the neutron source model because the main function of these components is to regulate the neutron flux of the core. For the MCAs, ADJs, and SORs, the geometry was explicitly modeled; however, ZCUs were implicitly modeled because of the complexity of their geometry. The reactivity device supporters attached to the inner wall of the calandria tank were homogenized as well. The mass and volume of the non-fuel component were preserved in the homogenization. The homogenization of the ZCU and reactivity supporter is explained in Reference 7.

When the neutron source model is established, the ex-core components such as the fuel adapter, lattice tube, shield plug, and end fitting should be modeled to the extent that they affect the neutron flux of the core. In the neutron source model, only a $50 \mathrm{~cm}$ region of the side structural components was considered, because it covers the region affecting the neutron flux distribution at the core, as discussed in Reference 7.

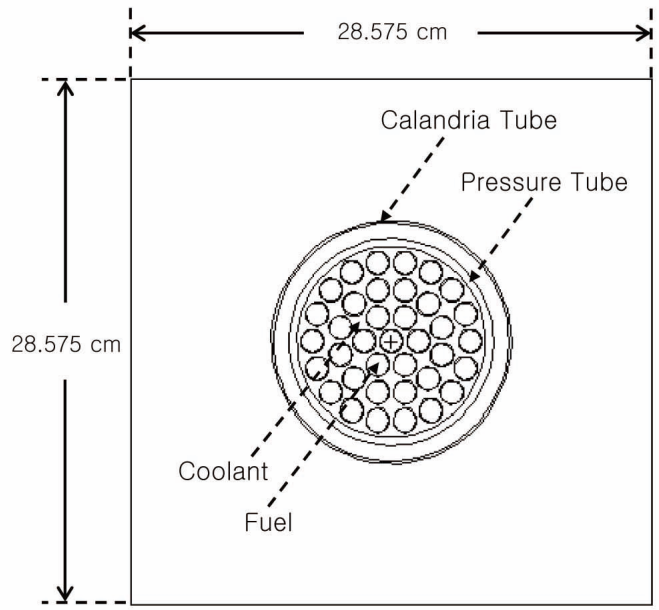

(a) explicit model

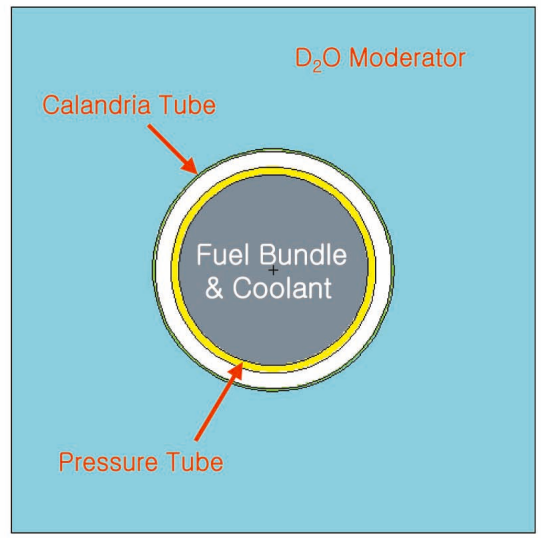

(b) implicit model

Fig. 2. Models for Fuel Lattice Descriptions. 


\subsubsection{Neutron Flux and Cross-section Calculation}

Finally, the time-average burned full-core model with the composition and geometry for the in-core and ex-core components described above was developed to represent the neutron source. Figure 3 shows the top view of the model developed by the MCNP.

A neutron transport calculation was performed to obtain the one-group neutron flux and one-group collapsed capture cross-sections. Continuous neutron cross-section libraries generated at 1,200 K, based on ENDF/B-VI nuclear data, were used for nuclides in the fuel. For the coolant and moderator, the cross-section library generated at $900 \mathrm{~K}$ and $600 \mathrm{~K}$ was used, respectively, for MCNP simulation.

The one-group neutron flux was estimated for the respective regions of the pressure tube, calandria tube, reactivity devices, reactivity device supporters, and calandria tank. The cross-section set for the activation calculation of in-core structural components such as the pressure tube, calandria tube, and reactivity devices was generated. Other cross-section sets for the activation calculation of ex-core components, such as reactivity device supporters and the calandria tank, were also generated by an MCNP full-core simulation.

\subsection{Activation Calculation}

In this paper, the structural component irradiated under the same neutron spectrum as the spectrum of the core is defined as an in-core structural component, whereas the structural component irradiated under a neutron spectrum different from the spectrum of the core is defined as an ex-core structural component.

\subsubsection{In-core structural component}

The following structural components were installed in the inner region of the core: the pressure tube, calandria tube, and reactivity device. It is known that, the smaller the region of the source term estimation, the better the obtained source term profile. In order to create a smaller evaluation volume, however, significant effort is required to prepare the input, run the code, and report the final results.

The source term calculation was performed for every $49.5 \mathrm{~cm}$ of pressure tube and calandria tube length, namely, with a neutron flux averaged over $49.5 \mathrm{~cm}$ of the tubes. This evaluation length is equivalent to the length of the fuel bundle. It needs to be noted that the node size in whole core reactor physics calculation performed by core management system of Wolsong Unit 1 is equivalent to lattice of one bundle $(28.575 \mathrm{~cm} \times 28.575 \mathrm{~cm} \times 49.5 \mathrm{~cm})$. That is to say, the length of bundle is treated as the axial length of node. This means that it is reasonable to consider neutron flux within a fuel bundle to be constant. This fact made us choose $49.5 \mathrm{~cm}$ as the size of evaluation length for pressure tube and calandria tube. When an inventory calculation is performed for the pressure tube and calandria tube, the cross-section set generated by weighting the incore neutron spectrum, as previously mentioned, was used in the ORIGEN2 calculation. The 4,560 values of

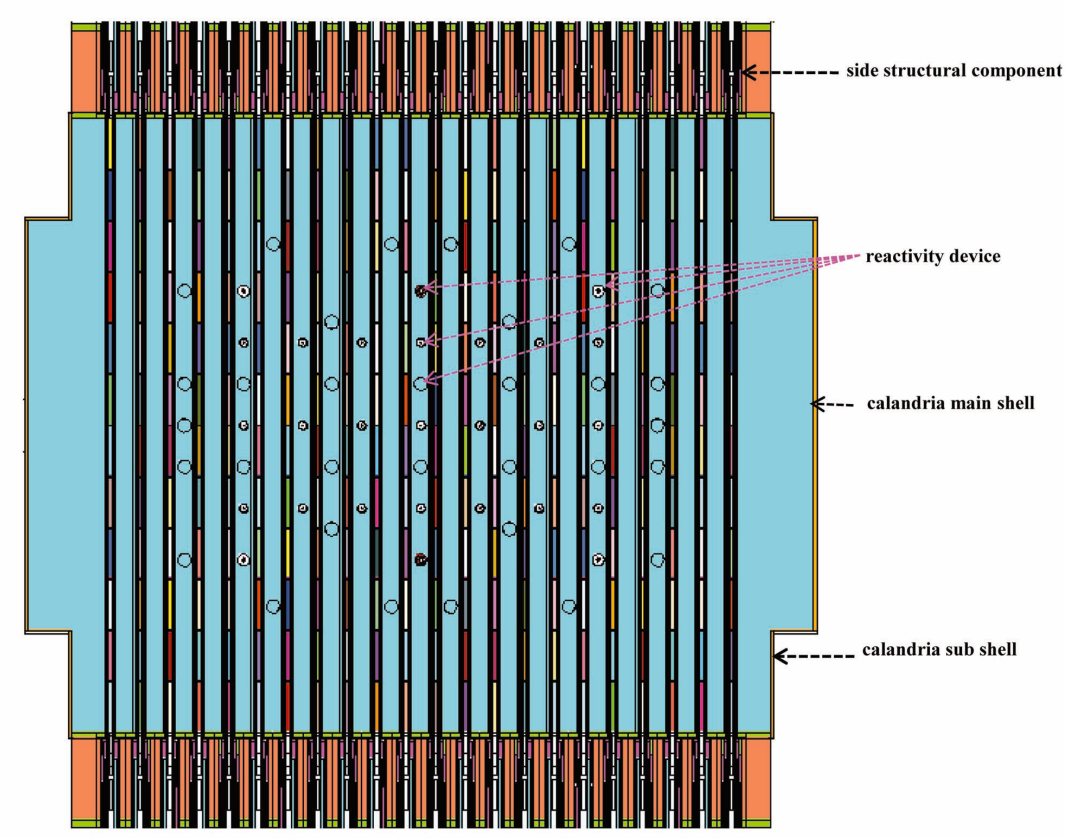

Fig. 3. Top View of the MCNP CANDU Core Model. 
source term data were obtained for the pressure tubes and calandria tubes, respectively.

For the reactivity devices, the source term was evaluated for each assembly of the reactivity device. The neutron flux and composition averaged over each reactivity device was used in the ORIGEN2 calculation. The same crosssection set generated by weighting the in-core neutron spectrum was used in the ORIGEN2 calculation as well. Because the inner core is comprised of $6 \mathrm{ZCUs}, 21 \mathrm{ADJ}$, $4 \mathrm{MCAs}$, and $28 \mathrm{SORs}, 59$ values of source term data were generated.

\subsubsection{Ex-core Structural Component}

The structural components such as the calandria tank, reactivity device supporters, and side structural components (SSCs) are installed in the outer region of the core. For the calandria tank, the source term calculation was performed for the main shell and two sub shells. For the reactivity device supporters, the source terms were evaluated for each position of the reactivity device as mentioned previously. The neutron flux and composition averaged over each reactivity device supporter were used in the ORIGEN2 calculation. When the source term evaluations of the calandria tank and reactivity device supporters were made, the cross-section set generated by weighting the neutron spectrum of the respective evaluation region was used in the ORIGEN2 calculation.

For the SSCs, a hybrid method for the source-term estimation was used. It should be recalled that SSCs are installed as a shield from neutron and gamma radiation, which means that it is difficult to obtain the neutron flux with good statistical precision and accuracy for the entire region of the SSC by an analog Monte Carlo simulation. As shown in Fig. 4(a), the length of the SSC is $245 \mathrm{~cm}$, which is too long to derive a reliable neutron flux and cross-sections through a full-core Monte Carlo simulation. Additionally, the neutron flux varies rapidly within the SSCs as a function of the distance from the center of the core. This means that it is inappropriate to evaluate the source term by dividing the entire SSC into one or two regions. Therefore, a method to decrease the computation time and increase the statistical precision was devised.

First, an explicit model of an SSC, as shown in Fig. 4(b), was divided into 12 homogenized regions, each with a length of $20 \mathrm{~cm}$ along the axial direction, except the last region, which is $25 \mathrm{~cm}$ in Fig. 4(c). Furthermore, the homogenized nuclide composition was generated considering the filling materials and associated volume for each region. The mass and total volume of the SSC in the explicit model were preserved in the homogenization. Therefore, the homogenized region is represented by one segment with $28.575 \mathrm{~cm} \times 28.575 \mathrm{~cm} \times 20 \mathrm{~cm}$.

In the sensitivity analysis, we considered two more models to find the appropriate homogenization for the radial direction. One is a three-region model that describes the SSC with inner, middle, and outermost regions along the radial direction. In this model, the inner and outermost regions contain only $\mathrm{D}_{2} \mathrm{O}$ coolant, and the middle region contains all the remaining structural components. The other is a two-region model in which homogenization was performed for two separate regions, namely, the inner and outer regions, containing a homogenized mixture for

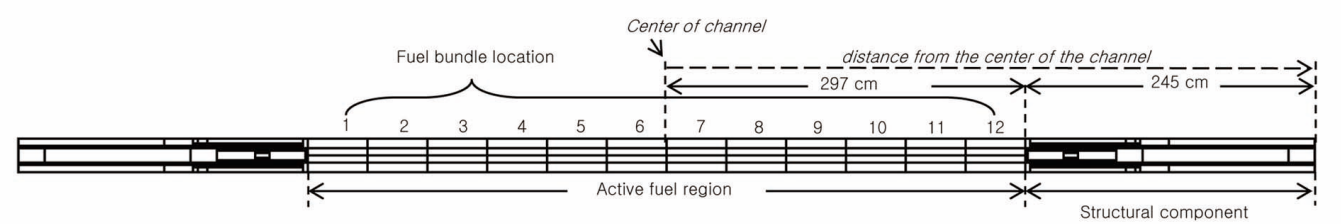

(a) Entire fuel channel model

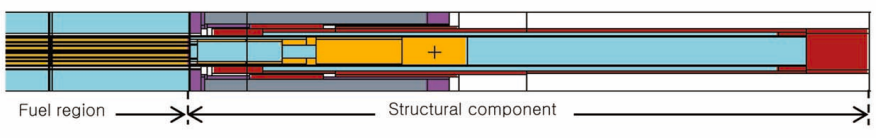

(b) Explicit model of side structural component

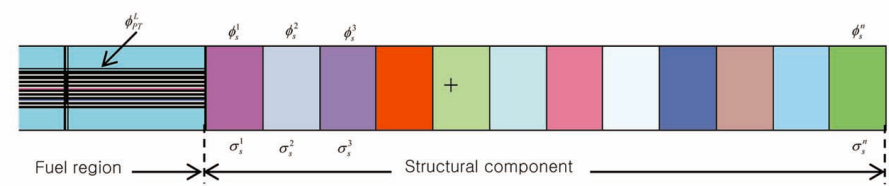

(c) Homogenized model of side structural component

Fig. 4. Configuration of the Single-channel Model. 
the coolant and structural materials, respectively. Because the difference in the specific activity of ${ }^{60} \mathrm{Co}$ between these four models including the explicit model was around $10 \%$, the simplest homogenization model with one segment was chosen in this study. Additionally, the fact that the $20 \mathrm{~cm}$ length along the axial direction revealed a difference of around $10 \%$ for the specific activity of ${ }^{60} \mathrm{Co}$ between the explicit and homogenized models determined this length.

The neutron flux of $\phi_{s}^{n}$ and cross-sections of $\sigma_{s}^{n}$ for each homogenized region of the SSC, and the neutron flux of $\phi_{P T}^{L}$ for the pressure tube at fuel bundle locations 1 or 12, as shown in Fig. 4(c), were calculated using the MCNP simulation with a single-channel model that represents only one channel of the CANDU reactor. In addition, the flux reduction ratio of $r^{n}$ for each region was calculated by dividing the neutron flux of the homogenized region by the neutron flux of the pressure tube, as described in Eq. (4):

$$
r^{n}=\left(\frac{\phi_{S}^{n}}{\phi_{P T}^{L}}\right)_{\text {single-channel model }} .
$$

The cross-sections of $\sigma_{S}^{n}$ for each homogenized region of the SSC were used for the ORIGEN2 activation calculation. The absolute flux of each homogenized region needed for the activation calculation was obtained by multiplying the absolute neutron flux of the pressure tube nearest the SSC by the flux reduction ratio of each region, as described in Eq. (5):

$$
\phi_{S}^{n}=r^{n} \times\left(\phi_{P T}^{L}\right)_{\text {full-core model }} .
$$

In Eq. $(5),\left(\phi_{P T}^{L}\right)_{\text {full-core model }}$ is the absolute neutron flux estimated from the MCNP simulation with a full-core model.

Figure 5 shows the hybrid method for the activation analysis of the SSC. For the region of $n$ for the SSC, Eqs. (1) and (2) can be expressed by using Eqs. (6) and (7), respectively:

$$
\begin{gathered}
\frac{d N_{i}^{n}}{d t}=\sum_{j} \delta_{i j} \lambda_{j} N_{j}^{n}+\sum_{k} f_{i k} \sigma_{s, k}^{n} \phi_{s}^{n} N_{k}^{n}-\left(\lambda_{i}+\sigma_{s, i}^{n} \phi_{s}^{n}\right) N_{i}^{n}, \\
\sigma_{s, i}^{n}=\frac{\iint \sigma_{s, i}^{n}(E) \phi_{s}^{n}(E)_{\text {single-channelmodel }} d E d V^{n}}{\iint \phi_{s, i}^{n}(E)_{\text {single-channelmodel }} d E d V^{n}},
\end{gathered}
$$

where $\sigma_{s, i}^{n}=$ a one-group collapsed capture cross-section for nuclide $i$ in region $n$.

Figure 6 shows the neutron flux variation estimated by the hybrid method using both full-core and singlechannel simulations. In Fig. 6, a rapid flux drop of around $400 \mathrm{~cm}$ from the center of the channel is caused by increased coolant in this region. Figure 7 shows the cross-section variation within the SSC derived from the single-channel simulation. The positions of $297 \mathrm{~cm}$ and $542 \mathrm{~cm}$ in figures 6 and 7 represent the inner and outer surface of the SSC.

It was not possible to obtain the neutron flux at the end region of the SSC through a Monte Carlo simulation with a full-core model. However, it was easy to retrieve the neutron flux at the end region of the SSC through a Monte Carlo simulation with a single-channel model. It was also easy to obtain the absolute neutron flux at a pressure tube located at fuel bundle locations 1 and 12 ,

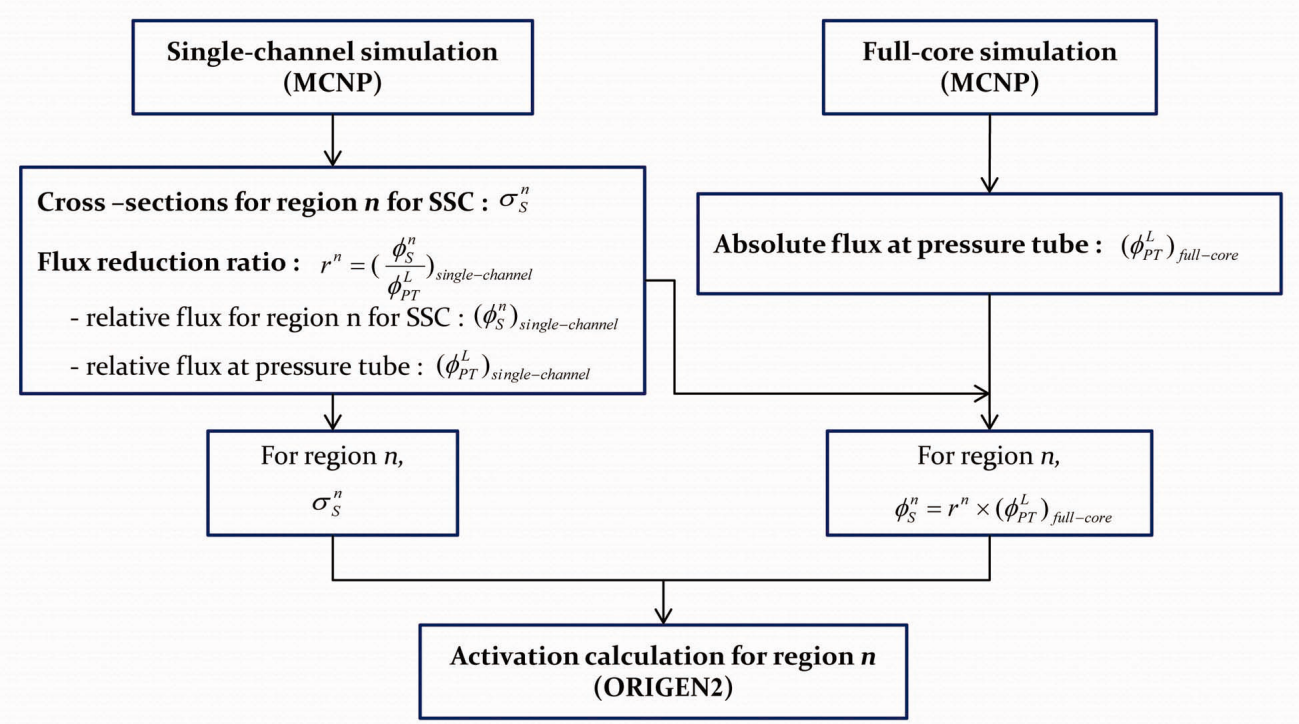

Fig. 5. Hybrid Method for Activation Analysis for the Side Structural Component. 


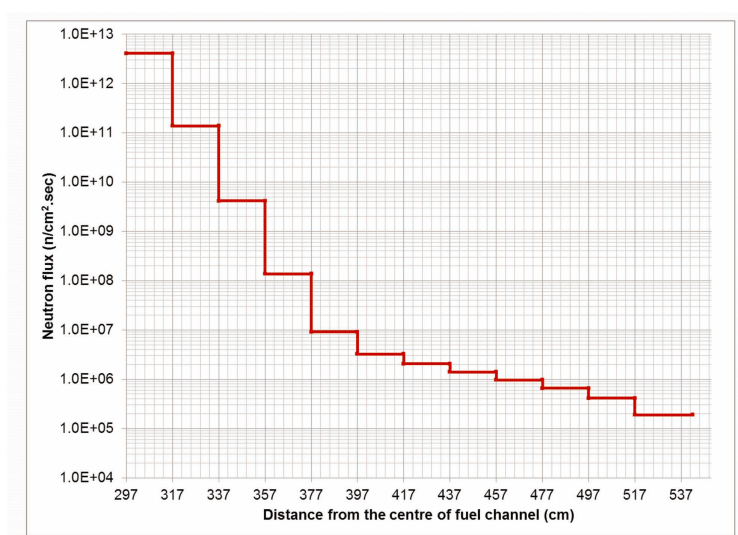

Fig. 6. Flux Distribution at the Central Channel of Wolsong Unit 1.

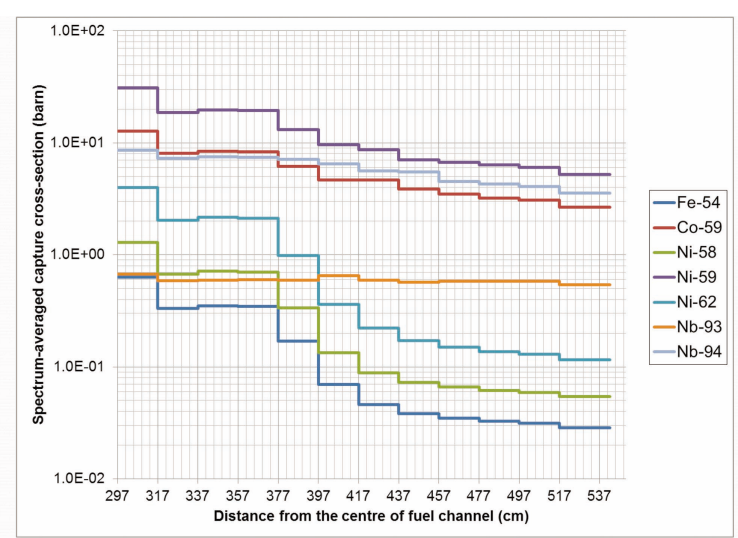

Fig. 7. Variation of the Cross-section Within the Side Structural Component. although the MCNP simulation with a full-core model was performed. By using the method mentioned above, it was possible to obtain the source term for the SSC taking into account the remarkably varying cross-section and three-dimensional neutron flux distribution without a computational burden.

Eventually, 3 values of data for the calandria tank, 59 values of data for the reactivity device supporters, and 9,120 values of source term data for the SSCs were obtained in this study.

\subsection{Reliability of Results}

In Reference 8, a method for establishing a time-average equilibrium core model and a source-term calculation method using a constant neutron flux and cross-section as a function of irradiation time for the characterization of decommissioning waste were verified by comparing the nuclide inventory estimated in the MCNP/ORIGEN2 simulations with the measured nuclide inventory according to a chemical assay in irradiated pressure tubes that were discharged from Wolsong Unit 1 in 1994.

Six locations from two pressure tubes having a profile of a 11.4-year irradiation and 15.1-year cooling times were sampled, and specimens were manufactured to measure the nuclide inventory in the irradiated pressure tubes. The initial composition of $\mathrm{Nb}$ in the specimens fabricated from the pressure tube was also quantified using a neutron activation analysis method using the HANARO research reactor in the Korea Atomic Energy Research Institute for its application as an input value for the radionuclide buildup calculation in ORIGEN2. The specific activity of ${ }^{94} \mathrm{Nb}$ was also quantified by measuring gamma rays emitted from fabricated specimens using a Compton suppression HPGe gamma ray spectrometer. The specific activity of ${ }^{94} \mathrm{Nb}$ was also estimated by the MCNP/ORIGEN2 system, taking into account the same profile and initial composition as the specimen. As a result, the values estimated from the analysis system agreed with the measured data within a difference range of $30 \%$. This evaluation provided confidence in the calculation method. Therefore, the estimated source terms of decommissioning waste from the CANDU reactor in this study have high reliability, as the same method considered in Reference 8 was used in this paper.

\section{RADIOLOGICAL CHARACTERISTICS AND WASTE CLASSIFICATION}

The source terms such as mass, radioactivity, decay heat, and hazard index for activated decommissioning waste from Wolsong Unit 1 were assessed on the basis of a reliable method as previously described without taking into account radioactive contamination. For the pressure tubes, calandria tubes, and SSCs, for which refurbishment was completed in 2010 , an irradiation period of 25 years was considered. For other waste such as the reactivity device, reactivity device supporter, and calandria tank, which were expected to be irradiated without refurbishment for the reactor lifetime, 50 years of irradiation time was assumed. The annual capacity factor of the reactor was assumed to be $85 \%$ over the reactor lifetime.

The radiological characteristics were analyzed on the basis of the concentration of the long-lived radionuclides related to waste classification, including ${ }^{3} \mathrm{H},{ }^{14} \mathrm{C},{ }^{60} \mathrm{Co},{ }^{59} \mathrm{Ni}$, ${ }^{63} \mathrm{Ni},{ }^{90} \mathrm{Sr},{ }^{94} \mathrm{Nb},{ }^{99} \mathrm{Tc},{ }^{129} \mathrm{I}$, and ${ }^{137} \mathrm{Cs}$, specified in both the South Korean standard MEST Notice 2009-37 [14] and the US standard 10 CFR 61 [15]. Because the MEST Notice 2009-37 classifies only low- and intermediate-level waste (LILW), the waste satisfying the Korean standard was classified as LILW, and the waste exceeding the Korean standard was classified as greater than disposal criteria 
Table 1. Source Terms and Waste Classification for Each Activated Waste.

\begin{tabular}{|c|c|c|c|c|c|c|c|}
\hline \multirow{2}{*}{$\begin{array}{c}\text { Structural } \\
\text { Component }\end{array}$} & \multirow{2}{*}{$\begin{array}{l}\text { Mass } \\
(\mathrm{kg})\end{array}$} & \multirow{2}{*}{$\begin{array}{l}\text { Volume } \\
\left(\mathrm{m}^{3}\right)\end{array}$} & \multirow{2}{*}{$\begin{array}{l}\text { Radioactivity } \\
\text { (Becquerel) }\end{array}$} & \multirow{2}{*}{$\begin{array}{l}\text { Thermal Power } \\
\text { (Watt) }\end{array}$} & \multirow{2}{*}{$\begin{array}{c}\text { Inhalation Hazard } \\
\text { Index }\left(\mathrm{m}^{3} \text {-water }\right)\end{array}$} & \multicolumn{2}{|c|}{ Waste Class } \\
\hline & & & & & & Kor-Std ${ }^{\text {a) }}$ & US-Std $^{\text {b) }}$ \\
\hline Pressure Tube & $2.180 \mathrm{E} 04$ & 3.317E00 & $7.712 \mathrm{E} 14^{\mathrm{c})}$ & $1.485 \mathrm{E} 02$ & $7.588 \mathrm{E} 13$ & GTDC & GTCC \\
\hline Calandria Tube & $8.316 \mathrm{E} 03$ & $1.291 \mathrm{E} 00$ & $3.518 \mathrm{E} 14$ & 2.777E01 & $1.005 \mathrm{E} 13$ & GTDC & GTCC \\
\hline Reactivity Device & $1.577 \mathrm{E} 03$ & $2.453 \mathrm{E}-1$ & $4.404 \mathrm{E} 15$ & $1.046 \mathrm{E} 03$ & 2.342E14 & GTDC & GTCC \\
\hline $\begin{array}{c}\text { Reactivity Device } \\
\text { Supporter }\end{array}$ & 7.033E02 & $8.930 \mathrm{E}-2$ & $3.218 \mathrm{E} 15$ & $8.628 \mathrm{E} 02$ & $1.991 \mathrm{E} 14$ & GTDC & GTCC \\
\hline Calandria Tank & $3.660 \mathrm{E} 04$ & $4.634 \mathrm{E} 00$ & $1.000 \mathrm{E} 15$ & 3.713E00 & $1.453 \mathrm{E} 13$ & GTDC & GTCC \\
\hline $\begin{array}{c}\text { Side Structural } \\
\text { Component }\end{array}$ & $4.003 \mathrm{E} 05$ & $6.423 \mathrm{E} 01$ & $6.781 \mathrm{E} 14$ & $1.033 \mathrm{E} 00$ & $2.892 \mathrm{E} 12$ & LILW & Class A \\
\hline Total & 4.693E05 & 7.380E01 & $1.042 \mathrm{E} 16$ & $2.088 \mathrm{E} 03$ & $5.313 \mathrm{E} 14$ & N/A & N/A \\
\hline
\end{tabular}

a) Korean standard; b) US standard; c) interpret as $7.712 \times 10^{14}$.

(GTDC) throughout this paper. Additionally, the GTCC represents waste greater than Class $\mathrm{C}$ specified in the US standard, which should be disposed of in a deep geological disposal repository. The radiological characteristics and resulting classifications were determined at a cooling time of 10 years after a permanent reactor shutdown.

For the pressure tube occupying $4.6 \%$ of the activated waste, it was discovered that only the concentration ${ }^{94} \mathrm{Nb}$ showed $10^{5}$-times higher specific activity than the specified limits in the Korean standard, thus representing a GTDC. The nuclide ${ }^{94} \mathrm{Nb}$ revealed $66 \%$ of the total radioactivity of the ten nuclides mentioned above, which indicates that the classification does not change as a function of the cooling time of the waste. The dominant isotopes were ${ }^{55} \mathrm{Fe},{ }^{60} \mathrm{Co},{ }^{134} \mathrm{Cs}$, and ${ }^{94} \mathrm{Nb}$, accounting for around $41 \%$, $16 \%, 13 \%$, and $29 \%$ of the total radioactivity of all activated nuclides for the pressure tube. Likewise, this waste was revealed to be GTCC according to the US standard. For the calandria tube having a portion of $1.8 \%$ of the activated waste, ${ }^{60} \mathrm{Co}$ and ${ }^{63} \mathrm{Ni}$ had $98 \%$ of the total radioactivity of the ten nuclides. However, the nuclide affecting the waste classification was only ${ }^{94} \mathrm{Nb}$, revealing 10-times higher specific activity than the limits specified by the Korean standards. The dominant isotopes were ${ }^{55} \mathrm{Fe},{ }^{60} \mathrm{Co},{ }^{63} \mathrm{Ni},{ }^{125} \mathrm{Sb}$, and ${ }^{125 \mathrm{~m}} \mathrm{Te}$, comprising about $14 \%$, $6 \%, 16 \%, 49 \%$, and $12 \%$ of the total radioactivity of all activated nuclides. ${ }^{94} \mathrm{Nb}$, which is important in the aspect of waste classification, revealed a portion of only $0.004 \%$ of the total radioactivity of all activated nuclides for the calandria tube. This waste was also GTCC in comparison with the US standards. For the reactivity device and its supporter, which form $0.5 \%$ of the activated waste, the nuclides ${ }^{14} \mathrm{C},{ }^{60} \mathrm{Co},{ }^{59} \mathrm{Ni}$, and ${ }^{63} \mathrm{Ni}$ exceeded the limits specified in both standards. Like a calandria tube, the major nuclides were ${ }^{55} \mathrm{Fe}{ }^{60} \mathrm{Co},{ }^{63} \mathrm{Ni},{ }^{125} \mathrm{Sb}$, and ${ }^{125 \mathrm{~m}} \mathrm{Te}$. For the calandria tank, the classification controlling radionuclides were ${ }^{59} \mathrm{Ni}$ and ${ }^{63} \mathrm{Ni}$. The nuclides ${ }^{55} \mathrm{Fe}$ and ${ }^{63} \mathrm{Ni}$ revealed $65 \%$ and $34 \%$ of the total radioactivity for all activated nuclides, respectively. For the SSC, reaching $85 \%$ of the decommissioning waste, there were no nuclides exceeding the limits. In the case of the SSC, the dominant isotopes were different for each region because of various filling materials. For the first homogenized region, which had the highest radioactivity, the dominant isotopes were ${ }^{55} \mathrm{Fe},{ }^{60} \mathrm{Co},{ }^{63} \mathrm{Ni},{ }^{125} \mathrm{Sb}$, and ${ }^{125 \mathrm{~m}} \mathrm{Te}$, with a portion of about $7 \%, 7 \%, 38 \%, 35 \%$, and $9 \%$ of the total radioactivity of all the activated nuclides.

Table 1 summarizes the source terms and resulting waste classification for each activated waste. The mass and volume are described first, followed by each source term and associated waste classification. The total value of each source term is listed: for example, the radioactivity $7.71 \times 10^{14}$ Becquerel indicates the total radioactivity of all the activated nuclides for all pressure tubes discharged from the decommissioning of CANDU reactors. As shown in the table, radioactivity, decay heat, hazard index, mass, and solid volume for the activated decommissioning waste were $1.04 \times 10^{16} \mathrm{~Bq}, 2.09 \times 10^{3} \mathrm{~W}, 5.31 \times 10^{14} \mathrm{~m}^{3}$-water, $4.69 \times 10^{5} \mathrm{~kg}, 7.38 \times 10^{1} \mathrm{~m}^{3}$, respectively. The activated waste of the pressure tube, calandria tube, reactivity device, and reactivity device supporter were classified as GTDC, whereas the SSC was classified as LILW. When the US standards were applied, the same results were obtained. Thus, our results confirm that, regardless of the cooling time of the waste, $15 \%$ of the decommissioning waste cannot be disposed of in a land disposal repository. 


\section{SUMMARY AND CONCLUSIOIN}

In this paper, the source terms and waste classification were assessed for neutron-activated decommissioning waste from a CANDU reactor. The MCNP/ORIGEN2 code system was used for the source term analysis. The neutron flux and activation cross-section library generated by an MCNP simulation were used in the radionuclide buildup calculation in ORIGEN2. The specific activities of the relevant radionuclides in the activated metal waste were compared with the specified limits of the specific activities listed in the Korean criteria and 10 CFR 61. The time-average full-core model of Wolsong Unit 1 was used as a neutron source for activation of in-core and ex-core structural components. The approximated levels for a neutron flux and cross-section, irradiated fuel composition, and a geometry simplification revealing good reliability in a previous study were used in the source term calculation as well.

The resulting radioactivity, decay heat, hazard index, mass, and solid volume for the activated decommissioning waste were $1.04 \times 10^{16} \mathrm{~Bq}, 2.09 \times 10^{3} \mathrm{~W}, 5.31 \times 10^{14} \mathrm{~m}^{3}$ water, $4.69 \times 10^{5} \mathrm{~kg}, 7.38 \times 10^{1} \mathrm{~m}^{3}$, respectively. According to both Korean and US standards, the activated waste of the pressure tube, calandria tube, reactivity device, and reactivity device supporter were classified as GTDC, whereas the SSC was classified as LILW. Our study demonstrates that $85 \%$ of the decommissioning waste can be disposed of in a land disposal repository.

Because there is no available data associated with neutron-activated decommissioning waste from a CANDU reactor, it is expected that the source terms and waste classification evaluated through this study can be widely used to establish a decommissioning strategy and fuel cycle analysis for CANDU reactors.

\section{ACKNOWLEDGEMENTS}

The authors acknowledge that this work was funded by the Ministry of Education, Science and Technology, Korea.

\section{REFERENCES}

[1] http://www.iaea.or.at/programmes/a2/, International Atomic Energy Agency, (2011).

[2] MKE Notice 2010-490, The $5^{\text {th }}$ Basic Plan of Electricity Supply and Demand (2010 2024), Ministry of Knowledge Economy, (2010).

[ 3 ] H. S. Kim, S. B. Sim, H. Y. Yang, D. K. Cho, and G. M. Sun, "Development Plan on Cost Estimation System for
Decommissioning of Nuclear Reactor in Korea," Transactions of the American Nuclear Society and Embedded Topical Meetings, Anaheim, California, USA, June 8-12, 2008, (2008).

[4] D. K. Cho, G. M. Sun, J. T. Jeong, H. J. Choi, J. W. Choi, D. H. Hwang, H. S. Kim, H. Y. Yang, T. W. Hwang, "Development of a Full-core CANDU Model for a Quantification of Decommissioning Wastes," Transactions of the Korean Nuclear Society Spring Meeting, Jeju, Korea, May 18-22, 2009, (2009).

[5] H. S. Kim and T. W. Hwang, "Major Cost Items for Decommissioning Cost Estimation," Proceedings of International Symposium on Radiation Safety Management, Daejeon, Korea, November 4-6, 2009, (2009).

[6] "Radiological Characterization of Shut Down Nuclear Reactors for Decommissioning," Technical Report Series, No. 389, International Atomic Energy Agency, (1998).

[7] D. K. Cho, G. M. Sun, J. W. Choi, D. H. Hwang, T. W. Hwang, H. Y. Yang, and D. H. Park, "Sensitivity of Physics Parameters for Establishment of a Burned CANDU FullCore Model for Decommissioning Waste Characterization," Journal of Nuclear Science and Technology, Vol. 48, No. 2, pp. 215-226, (2011).

[ 8 ] D. K. Cho, G. M. Sun, J. W. Choi, H. Y. Yang, and T. W. Hwang, "Verification of Source Term Estimation Method against Measured Data for Decommissioning Waste from a CANDU Reactor," Journal of Nuclear Science and Technology, Vol. 48, No. 7, (2011).

[9] "Design Manual: CANDU 600 Generation Station Physics Design Manual,” DM-59-01100, Atomic Energy of Canada Limited, (1980).

[10] X-5 Monte Carlo Team, "MCNP-A General Monte Carlo N-Particle Transport Code, Version 5," LAUR-03-1987, Los Alamos National Laboratory, (2003).

[11] G. Croff, “A User's Manual for the ORIGEN2 Computer Code," ORNL TM-7175, Oak Ridge National Laboratory Report, (1980).

[12] E. F. Love, K. A. Pauley, and B. D. Reid, "Use of MCNP for Characterization of Reactor Vessel Internals Waste from Decommissioned Nuclear Reactors," INEL-95/0419, Idaho Technologies Company, (1995).

[13] R. Ahmed, D. K. Cho, H. J. Choi, J. W. Choi, and G. Y. Heo, "Influence of Cross-section on the Estimated Source Terms of Side-Structural Components in CANDU Reactor," Transactions of the Korean Nuclear Society Autumn Meeting, Jeju, Korea, October 21-22, 2010, (2010).

[14] MEST Notice 2009-37, Acceptance Criteria for Low- and Intermediate-level Waste, Ministry of Education, Science and Technology, (2009).

[15] 10 CFR 61, Licensing Requirements for Land Disposal of Radioactive Waste, U.S. Nuclear Regulatory Commission, (1992). 